\title{
Technology Effects in Distributed Team Coordination-High-Interdependency Tasks in Offshore Oil Production
}

\author{
Petra Saskia Bayerl \& Kristina Lauche \\ Faculty of Industrial Design Engineering, Delft University of Technology, Landbergstraat 15, Delft \\ 2628 CE, The Netherlands (Phone: +31-15-2785054; Fax: +31-15-2787316; E-mail: p.s. \\ bayerl@tudelft.nl;E-mail:k.lauche@tudelft.nl)
}

\begin{abstract}
For highly interdependent yet location-specific tasks, distributed teams need to closely coordinate activities and processes. This field study in the upstream oil and gas industry focused on challenges in the coordination of highly interdependent tasks if teams work remotely on an ongoing basis. Based on 78 semi-structured interviews and observations over a period of 12 months, we identified coordination requirements for primary team activities, as well as effects of changing media capabilities to overcome difficulties of ongoing distribution. Implications for media requirements in the support of ongoing distributed teams are discussed.
\end{abstract}

Keywords: computer-mediated communication, coordination, distributed teams, task interdependency

\section{Introduction}

Work processes in teams require the continuous coordination of resources to accomplish common goals and react to changing organizational priorities. The use of computer integrated production management has helped to make coordination in teams more flexible and to support ever more complex processes. When computer aided or integrated manufacturing (CAM/CIM) was first hailed as the solution to the challenges awaiting businesses in the Western world in the $1980 \mathrm{~s} / 90 \mathrm{~s}$, the concept was largely technology driven. However, many of the seminal studies in CSCW found that the use of technology alters the practices of coordination and may create problems if the social organization of cooperative work is disregarded (e. g., Harper et al. 1989; Heath and Luff 1992; Zuboff 1988). Similarly, researchers in work psychology have pointed out that CIM needs to be accompanied by an appropriate work organization such as semi-autonomous teams if the promises of reduced losses and increased flexibility are to be realized (Kirsch et al. 1994; Pardo et al. 1994). Although the reality did not always live up to the rhetoric of these management concepts, many firms successfully changed how they manage their production. 
With some delay, this change of work practices to more computer integrated monitoring and concurrent planning has also reached the less stationary industries such as construction or the exploration and production of hydrocarbons (Lauche 2008). While some transient industries such as aviation have been studied extensively (e. g., Fields et al. 2005; Harper et al. 1989), those traditionally considered 'low tech' are still under-researched in CSCW. On construction sites or drilling rigs simple things like a regular update of current production figures on a central server were only worth considering, once remote sites had reliable and fast access to the central ICT of their companies. Prior to the advancement of ICT capacity and cheap bandwidth, the planners and engineers in the headquarter would prepare drawings, work programs, and schedules up to a certain degree of detail and leave the actual implementation and troubleshooting to those on the remote site. This Tayloristic division of labor that assigned 'thinking' and 'doing' to distinct groups therefore was not only rooted in historical power differences, but had rather practical reasons, as physical access to the remote site is by necessity restricted and the exchange of information between remote partners remains cumbersome. Now that the advancement of ICT and improved bandwidth have theoretically enabled real-time data transmission to pretty much any remote site around the globe, planners and on-site mechanics can in fact communicate in 'real-time' and update their process models on a continuous basis with the newest information.

Assuming that the integration of computerized process monitoring is, in principle, a similar undertaking in the construction industry or semi-automated process industries such as oil and gas exploration and production, there should be lessons learned from the earlier studies of CAM/CIM that would be worth considering. The work on collective action regulation in teams showed that teams that were given a higher degree of autonomy in coordinating their internal resources, carrying out detailed planning and cross-training were not only more flexible and efficient but also better at knowledge sharing and cohesion (Weber 1997). The general design principle from this earlier work has been to delegate responsibility as far as possible to the sharp end (Clegg 2000). Another important aspect identified in the manufacturing industry is that of boundary regulation between semi-autonomous teams: while subteams can function well based on their internal coordination, some form of boundary spanning is required between teams whose actions can impact on one another (Zölch 1999). The higher the interdependency between tasks, the more important coordination becomes. Artman and Waern (1999) and Petterson et al. (2004) have described how call takers and dispatchers in emergency response teams create common ground with callers and response personnel. For unmanned space exploration, research teams with relative low task interdependency were found to benefit from simultaneous access to real-time data, as more people could participate in the collaboration and scientists could adapt their models based on real-time data (Olson and Olson 2000). However, 
manned space exploration involves more task interdependency in the dynamic interaction between astronauts and flight controllers. Thus more scripted roles were required for who should listen in and who may issue requests (Patterson et al. 1999; Patterson and Woods 2001).

The advance of ICT into traditional 'low tech' industries is likely to progress and become more pronounced as improvements of infrastructure reach increasingly remoter locations. But the question remains whether better access is a positive development in all cases and for all involved. The safety-critical nature of many tasks in these areas makes it crucial that ICT changes do not lead to additional disruptions of established routines and processes. It is important therefore to obtain a better understanding of how different technologies may affect cooperation and coordination in such teams. In the present paper, we report findings from a field study in the offshore oil industry, in which we investigated changes in the ongoing coordination in distributed production teams due to the implementation of new ICT. The main rationale of our study was to investigate effects of changing technologies on the coordination and cooperation in distributed production teams in terms of every-day coordination processes.

Unlike most domains covered in the existing research about distributed working (e. g., management, design, or student teams; Hammond et al. 2005; Jarvenpaa and Leidner 1999; Kirkman et al. 2004), geographic distribution in oil and gas exploration and production is not due to strategic business decisions, but a result of the nature of the task. The work at the 'sharp end' is by its very nature remote and risky, which in turn means that support functions and managerial staff are preferably not spread out across all rigs but centrally located. Similar forms of distributed coordination can be found in domains such as construction, military, emergency response, aviation and space flight. Compared to space flight and aviation, however, collaboration in the oil and gas industry is less proceduralized and rather driven by market fluctuation and performance. Oil production is further characterized by mostly continuous processes, compared to the more project-based nature of other areas like space exploration, military operations, or construction. It features complex, dynamic tasks with rich practices of collaboration in existing subgroups with a legacy of different tools and cultures. A feature the oil and gas industry shares with space exploration or military is that many tasks are highly safety-critical and require specialist training for survival in an unwelcoming and potentially harmful environment.

\section{Methods}

\subsection{Organizational context}

Our study was conducted at one branch of a globally operating oil and gas exploration company. During the course of the study this company implemented new communication and information technologies, namely video-conferencing, 
desktop-sharing, and real-time access to plant and process data, in addition to existing media (mainly phone, email, and audio-conferencing). The rationale for the implementation was to improve cooperation between the office and the rig side, i. e., onshore and offshore personnel.

\subsection{Participants and procedure}

We conducted 78 semi-structured interviews with personnel from various functions onshore and offshore (see Table 1 for an overview). Questions covered the type and frequency of onshore-offshore contacts, communication partners and rationales, the technology used for these contacts, as well as individual tasks and responsibilities within the teams. During the interviews we also asked specifically for experiences with the new ICT and how implementation had changed team processes and relations between the two subgroups. The interviews lasted between 30 and 90 min (avg. about $60 \mathrm{~min}$ ). All interviews were recorded on tape and transcribed verbatim prior to analysis. The first author was located on site in the office and over the course of 12 months regularly conducted workplace observations of onshore meetings and normal work situations, as well as episodes of critical incidents. In addition, observations offshore were conducted by the first author during 2-5 day visits to two offshore installations. Information on media use, frequencies, and rationales for media choices were based on self-reports in the interviews as well as observations.

\subsection{Data analysis}

Interviews were content analyzed using thematic coding in Atlas-ti. The main focus of the analysis lay on descriptions of how subgroups coordinated individual tasks and the role diverse media played in their support. In a first step we identified specific onshore and offshore roles, tasks, and functions as well as coordination requirements between the two subgroups. Based on these descriptions we identified primary activities in which coordination between onshore and

Table 1. Type and number of onshore and offshore personnel interviewed.

\begin{tabular}{lclr}
\hline Onshore functions & $\#$ & Offshore functions & $\#$ \\
\hline TEAM MEMBERS & 39 & Technicians & 7 \\
Support engineers & & Petroleum engineers & 3 \\
& & & \\
MANAGERS & 6 & Team leaders & 5 \\
Team leaders & 4 & Operations engineers & 6 \\
Technical authorities & 3 & Installation managers & 5 \\
Field operations managers & 52 & Total offshore & 26 \\
Total onshore & & & \\
\hline
\end{tabular}


offshore personnel was needed. We did not have a-priori assumptions on how media use would change coordination; instead we aimed to find new 'emerging' patterns (Glaser 1992). We therefore started with an open coding technique (Walsham 1995), using high-level codes to categorize statements with respect to the primary activities. For each primary activity we then coded the type of medium used, usage patterns such as frequencies or preferences, and comments on the positive or negative aspects of a medium for this task (e. g., ability to document requests in emails versus inability to check for comprehension). We also specifically marked examples and episodes that illustrated positive or negative aspects of media, as well as statements that illustrated modifications in the coordination between subgroups due to the changes in technology. As we were interested in the impact of technology changes in a distributed setting, we used our initial codings to contrast statements and experiences from onshore and offshore participants. The longitudinal nature of the study further allowed us to sketch changes in coordination over time comparing statements of participants before, shortly after, and several months after the implementation. We used the team observations to obtain a first hand impression of team coordination and media use, but also to validate interview statements by our participants.

\section{Results}

\subsection{Subgroup roles and primary team activities}

"The fact that we're hundreds of miles apart [...] if you don't coordinate you're going to fall off the face of the earth." [onshore team leader]

As this first quote demonstrates, close coordination between subgroups was perceived as an indispensable part of every-day work processes in production teams. Onshore and offshore personnel typically described their overall team task as "to keep the plant running, exporting gas at a maximum rate". Our participants made it very clear, however, that the degree of involvement and the dependence of office and rig were not uniform over the production process. In stark simplification, most participants considered planning the task of onshore staff, which then "hands over to offshore for execution". This division was accepted and expected by both sides, as the following comment by an offshore technician shows:

"In an ideal world the guys offshore would love to be given a bag with all their tools, all their equipment, all their spares, and be taken aside and said, 'Right, there you go, that is yours; for the next two days, don't come back and see us ever again until it is finished'."

Onshore engineers saw their main tasks in the translation of business or strategic decisions into manageable work packages for offshore, the prioritization of work packages, the control of work with respect to technical and legal standards, vendor 
management, and engineering support in case of operational problems. Offshore personnel, in contrast, saw their role optimally as "purely execution" including the monitoring and control of production equipment, and the maintenance of equipment and plant. As a rough generalization, most tasks offshore could be characterized as primarily mechanical/technical (at least at the lower levels of the offshore organization), whereas tasks onshore were consistently of an intellectual/analytic nature (Driskell et al. 1987). As we will show later, this clear role differentiation became somewhat blurred by the implementation of additional ICT capabilities.

The divide in roles and responsibilities was also reflected in the demographics and work patterns of the two groups. Onshore personnel were characterized by a much higher number of university educated engineers and a larger number of younger and female staff, compared to offshore personnel. Onshore personnel further kept normal office hours (eight hours, Monday to Friday), while offshore staff operated on twelve hour day and night shifts for seven days a week. The physical working conditions for onshore and offshore workers are shown in Figure 1, which presents typical environments in the office onshore and on the rig offshore.
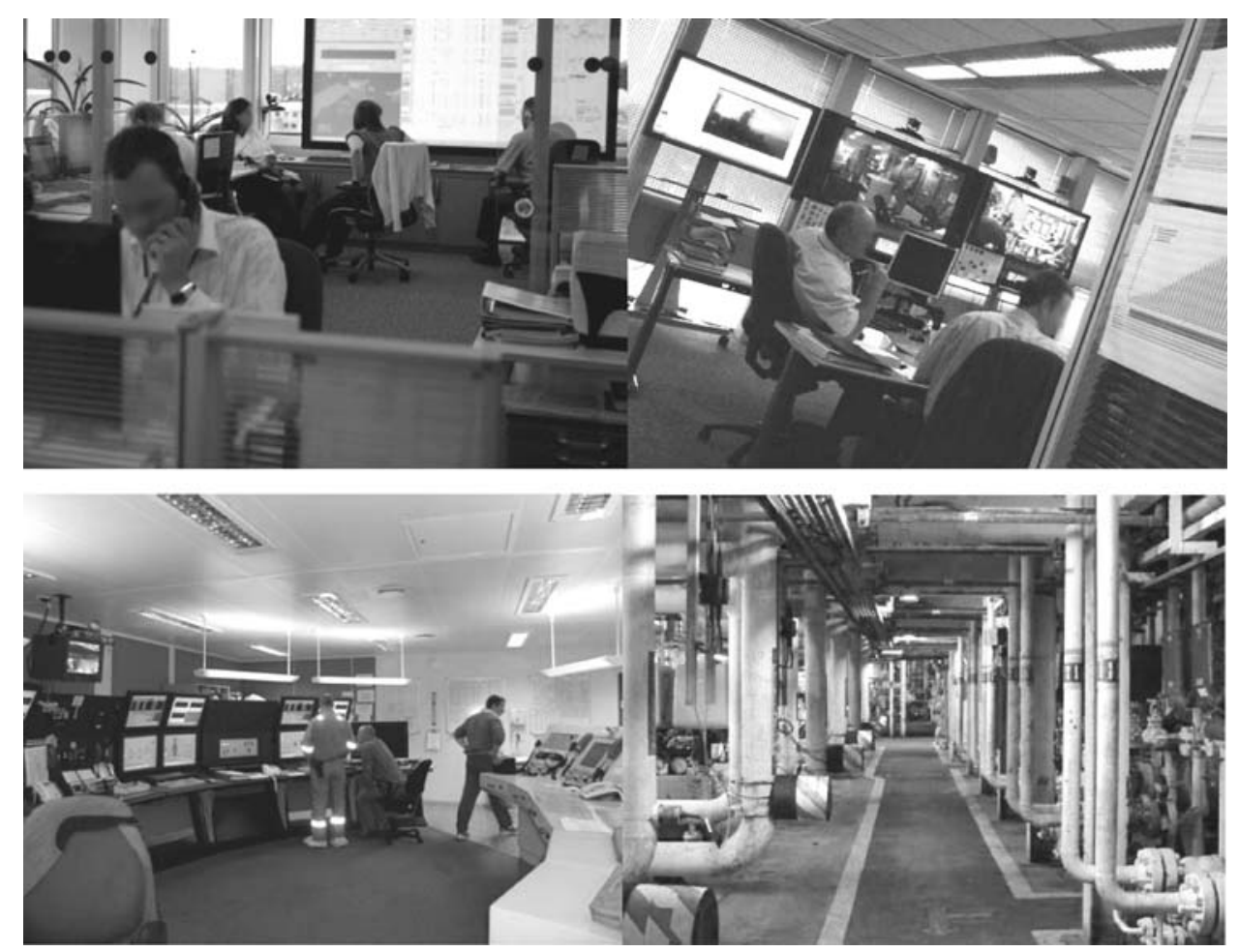

Figure 1. Typical work environments onshore and offshore. Top two pictures: team areas in the onshore office; bottom left: view of the main console in a central control room offshore; bottom right: part of the production area on an oil platform. 
In total, we found three major areas in which coordination between onshore and offshore was required on a regular basis:

1. well and plant configuration for optimized production,

2. planned and unplanned maintenance of the offshore installation, and

3. upset response, i. e., reactions to unexpected events.

Across all three areas, we identified nine primary activities members had to engage in on an ongoing basis to accomplish the team task. These were planning, executing, monitoring, reporting/informing, trouble-shooting, negotiating, coordination across team boundaries, documenting, and networking/maintenance of social relationships. Not all of these tasks were of equal criticality, however. Only the first five of the these activities, namely planning, executing, monitoring, reporting/informing, and trouble-shooting, can be considered as critical, in the sense that without them the overall team task could not be achieved. Many of the tasks were of a cyclic nature in that they reappeared again and again in a similar way, often guided by written procedures and detailed guidelines. Reporting/informing, for instance, was generally done in routinely scheduled meetings between the onshore and offshore subgroups throughout the week on a fixed agenda of topics (e. g., morning reports, maintenance planning, production optimization, health and safety). Activities also differed in the degree of 'scriptedness' or reliance on existing rules and regulations. Planning, for example, followed a stringent procedure, which determined who was to be involved at what stage and for which clearance had to be achieved before a task could pass through consecutive planning gates. Similarly, execution of tasks offshore relied on a detailed planning and reporting system for every single activity to guarantee that jobs could be executed on time and to prevent overlaps between several hazardous jobs at the same location. Activities like executing and monitoring in contrast to trouble-shooting also demonstrate that activities differed in their duration or cyclical nature. Monitoring required continuous 24/7 attention, whereas trouble-shooting activities only became relevant if critical events occurred. Monitoring can thus be considered an ongoing task, troubleshooting a sporadic activity. Reporting/informing and planning lay somewhere in between, as they occurred on regular basis, but were not required in the same ongoing manner as monitoring activities.

Due to the distribution of responsibilities between office (planning and support) and rig (execution and maintenance) and the different physical access to plant and equipment, the responsibilities for primary tasks and the degree of involvement of onshore and offshore personnel varied considerably. Tasks such as planning and coordination across team boundaries were clearly driven and guided by onshore, while others such as execution and monitoring were by necessity located offshore. Table 2 provides a summary of the nine activities with respect to responsible group, task criticality, its cyclic nature (ongoing, cyclic, sporadic), and degree of scriptedness (high vs. little or no reliance on standardized procedures). 
Table 2. Characteristics of primary team activities.

\begin{tabular}{|c|c|c|c|c|}
\hline Activity & Criticality & Responsible group & Cyclic nature & Scriptedness \\
\hline 1. Planning & High & Primarily onshore & Cyclic & High \\
\hline 2. Monitoring & High & Primarily offshore & Ongoing & Low \\
\hline 3. Execution & High & Offshore & Ongoing & High \\
\hline 4. Reporting/informing & High & Both & Cyclic & Medium \\
\hline 5. Trouble-shooting & High & Both & Sporadic & Low \\
\hline 6. Negotiating & Medium & Both & Sporadic & Low \\
\hline 7. Documenting & Medium & Both & Cyclic & Medium \\
\hline $\begin{array}{l}\text { 8. Coordination across } \\
\text { team boundaries }\end{array}$ & Medium & Primarily onshore & Sporadic & Low \\
\hline 9. Networking & Low & Both & Both & Both \\
\hline
\end{tabular}

\subsection{Communication and information exchange: Media availability and use}

Teams had access to two sets of technologies to support the cooperation between remote subgroups on a daily basis: communication technologies and tools for data exchange. In the 'traditional' setting, i. e., before the implementation of additional ICT, communication technologies consisted of phone, fax, mail, email, and audio-conferencing. A common way to exchange data between onshore and offshore was the attachment of spreadsheets, drawings, photos, or presentation slides to emails. Planning software was available for the planning and scheduling of tasks, in which the order of jobs, their interdependence, and logistic requirements such as personnel, tools, materials, or men hours were specified. This planning software was accessible only to a restricted number of people involved in the planning of jobs, i. e., planners and schedulers onshore, as well as managers offshore. For the access to information on plant and equipment status as well as production numbers onshore engineers could log into data bases, which provided a regularly updated overview of the most important offshore systems. The degree of detail differed, however, compared to information available offshore, which from time to time led to conflicts between subgroups:

"You can actually make two different decisions on the same data. The sample time is different, because [onshore] it only scans it 10 times a minute. And here offshore it's 60 times a minute [...] the average can end up different. [...] A good example is, we took some data and I made a decision that one of our systems doesn't blow down, doesn't get rid of the gas quick enough. If you look at the pie data [onshore], we were told, 'you have to open, keep this valve always open'. We looked at the data of the [offshore system] and said, 'no, that's nuts'. So you got these two bits of data, and we're trying to convince the guy onshore, who's not got the real-time data, that it's true." [offshore installation manager]

This situation changed with the installation of large data screens in the team areas onshore, which presented continuously updated information on production 
numbers and well status. This data were driven by the same systems that displayed information in the offshore control room panels and provided thus a 'real-time' picture of processes offshore. (Bandwidth restrictions reduced the sample rate from some platforms, but the general refresh rate was still higher than before.) For the better exchange of information, desktop-sharing capabilities were added to allow simultaneous screen and system manipulations by multiple members onshore and offshore. The implementation of the new ICT also added continuous video-conferencing (VC) links and at times cameras for individual use for communication between subgroups. The video-links connected the onshore team areas with the central control room offshore and at a later stage also with offices and meeting rooms offshore. The cameras were directed so that the picture showed most of the onshore team area and large parts of the control or meeting rooms. The organization expected that these new ICT would have "the potential to significantly re-align onshore and offshore teams around the common goal of the safe and cost efficient extraction of hydrocarbons" and "enable onshore and offshore staff to work together more effectively using advanced software and dedicated comms links to platforms, vendors and [company] experts around the world" (internal documents). Figure 2 shows the video-links between the onshore office and the control room offshore; Figure 3 gives an example for the data screens in the team areas onshore. Part of the organizational implementation strategy was the standardization of the onshore office environment across all teams in terms of ICT, as well as physical layout. The arrangements shown in Figures 2 and 3 were therefore typical for all production teams in this organization.

According to Clark and Brennan (1991), capabilities of media can be described with respect to eight characteristics that determine the nature of communication: copresence (group members occupy the same physical location), visibility (group members can see one another), audibility (group members can hear one another), cotemporality (communication is received at the approximate time it is sent),

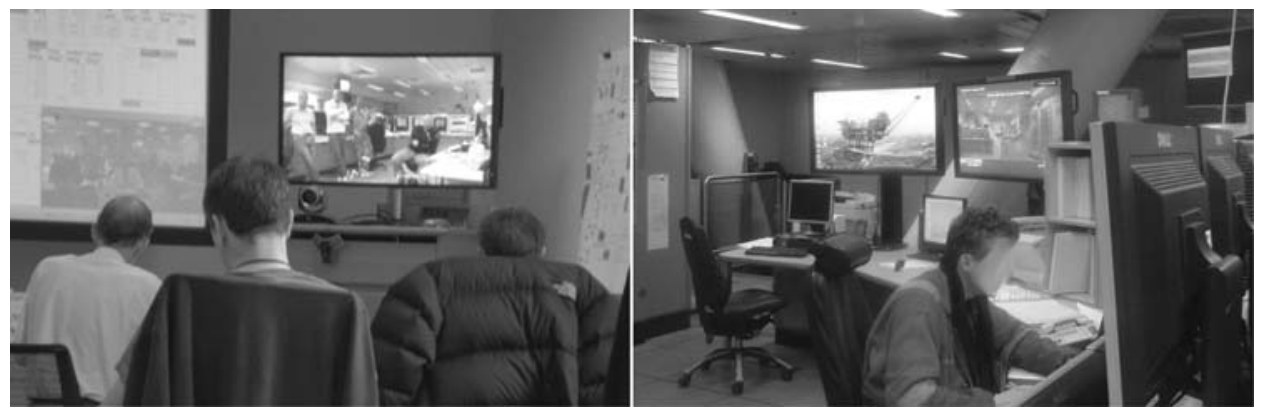

Figure 2. Use of the video-link in the onshore office during a meeting with offshore (left) and video-screens from the central control room into the office (right). 


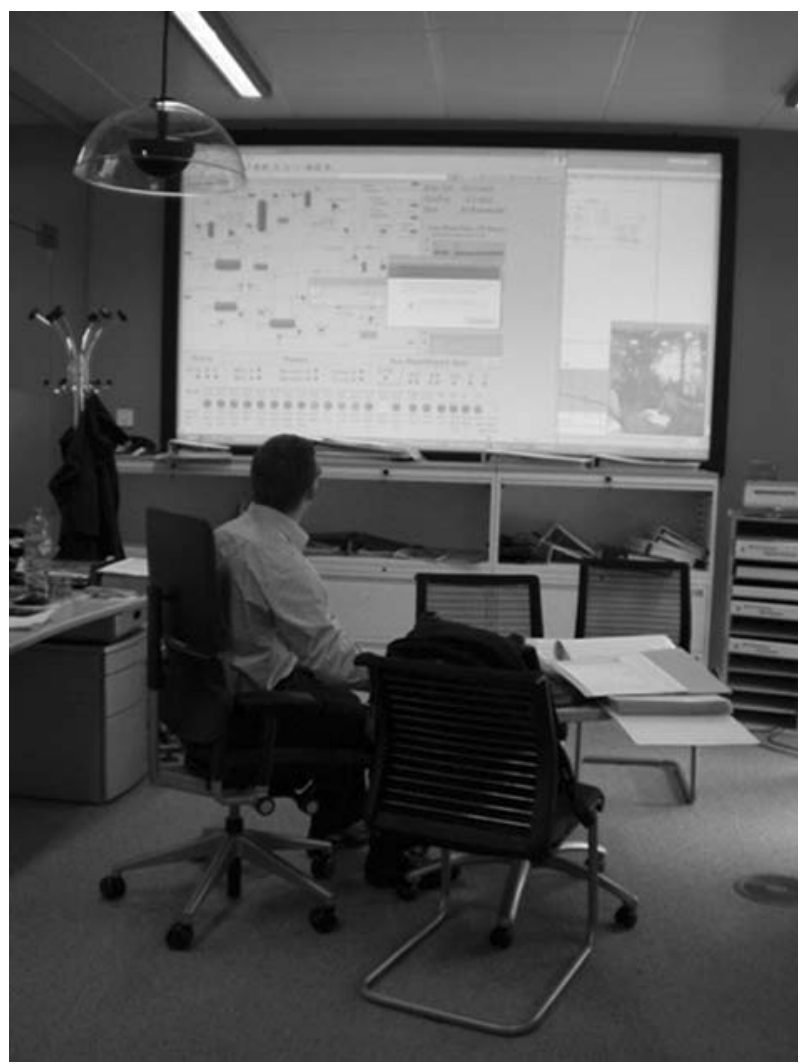

Figure 3. Screen in the onshore office for the display of real-time offshore data.

simultaneity (group members can send and receive messages simultaneously), sequentiality (group members speaking turns stay in sequence), revisability (messages can be revised before being sent), and reviewability (messages do not fade over time). Usually, these aspects are considered in terms of interactions between human actors. For the purpose of our study we extended this framework to the exchange and availability of data and information. This differentiation seemed important to capture the full complexity of the media mix available to teams and to better understand the effects of the newly implemented ICT. Table 3 gives an overview of traditional and new ICT capabilities based on the eight dimensions described by Clark and Brennan (1991). As can be seen, the new ICT added copresence, cotemporality, and visibility for personal interactions, augmenting phone and email, and replacing audio-conferencing with video-links. The data screens added visibility, cotemporality, simultaneity, and sequentiality to processes on the plant. Desktop sharing tools further added cotemporality, simultaneity, and sequentiality for data exchange.

Direction and frequency of contacts between the two subgroups differed according to the three major areas for coordination, i. e., well and plant configuration 
Table 3. Capabilities of traditional and new ICT (dimensions based on Clark and Brennan 1991).

\begin{tabular}{|c|c|c|c|c|c|c|c|c|}
\hline & \multicolumn{5}{|c|}{ Traditional ICT } & \multicolumn{3}{|c|}{ New ICT } \\
\hline & $\begin{array}{l}\text { Mail/ } \\
\text { email }\end{array}$ & $\begin{array}{c}\text { Email } \\
\text { attachment }\end{array}$ & Phone & $\mathrm{AC}$ & $\begin{array}{c}\text { Planning } \\
\text { system }\end{array}$ & $\mathrm{VC}$ & $\begin{array}{c}\text { Data } \\
\text { screens }\end{array}$ & $\begin{array}{l}\text { Desktop } \\
\text { sharing }\end{array}$ \\
\hline \multicolumn{9}{|l|}{ COMMUNICATION } \\
\hline Copresence & & & & & & $\mathrm{x}$ & & \\
\hline Visibility & & & & & & $\mathrm{x}$ & & \\
\hline Audibility & & & $\mathrm{x}$ & $\mathrm{x}$ & & $\mathrm{x}$ & & \\
\hline Cotemporality & & & $\mathrm{x}$ & $\mathrm{x}$ & & $\mathrm{x}$ & & \\
\hline Simultaneity & & & $\mathrm{x}$ & $\mathrm{x}$ & & $\mathrm{x}$ & & \\
\hline Sequentiality & & & $\mathrm{x}$ & $\mathrm{x}$ & & $\mathrm{x}$ & & \\
\hline Reviewability & $\mathrm{x}$ & & & & & & & \\
\hline Revisability & $\mathrm{x}$ & & & & & & & \\
\hline \multicolumn{9}{|c|}{$\begin{array}{l}\text { DATA/INFORMATION } \\
\text { Copresence }\end{array}$} \\
\hline Visibility & & & & & & $\mathrm{x}$ & $\mathrm{x}$ & $\mathrm{x}$ \\
\hline Audibility & & & (x) & (x) & & $\mathrm{x}$ & & \\
\hline Cotemporality & & & $(\mathrm{x})$ & $(\mathrm{x})$ & & $\mathrm{x}$ & $\mathrm{x}$ & $\mathrm{x}$ \\
\hline Simultaneity & & & & (x) & & $\mathrm{x}$ & & \\
\hline Sequentiality & & & & (x) & & $\mathrm{x}$ & $\mathrm{x}$ & $\mathrm{x}$ \\
\hline Reviewability & $\mathrm{x}$ & $\mathrm{x}$ & & & $\mathrm{x}$ & & $\mathrm{x}$ & \\
\hline Revisability & $\mathrm{x}$ & $\mathrm{x}$ & & & $\mathrm{x}$ & & & $\mathrm{x}$ \\
\hline
\end{tabular}

$A C$ audio-conferencing, $V C$ Video-conferencing; features in gray mark additional characteristics of new ICT, $(x)$ verbal information only, no data

for optimized production (primarily from onshore to offshore), planned and unplanned maintenance of the offshore installation (primarily onshore to offshore), and upset response (first contact from offshore to onshore, further contacts bidirectional, see detailed discussion of activities below). The main reasons for onshore contacts with offshore were the need for input in planning and decisions, the need for additional up-to-date information on the status of the plant or specific equipment, requests for actions such as chemical sampling or well tests, and suggestions for changes in the plant configuration to optimize or re-establish normal production. Contacts from offshore were driven primarily by requests for help and technical assistance during unexpected events, as well as routine status reports on conditions and production in the context of planned meetings.

The self-reported frequencies of contacts between onshore and offshore varied considerably. Asked how often participants communicated with their colleagues of the other subgroup, answers ranged from 1 to 300 times per week with an average of 37.5 times $(s d=47.7)$. At first sight the large range in communication frequencies may surprise. Yet, our sample consisted of multiple functions (planners, production engineers, offshore installation managers, control room technicians, etc.), which differed considerably in how closely they needed to coordinate with the other subgroup. These numbers moreover are self-reports and must therefore be taken with caution. Our observations, however, substantiated considerable variation in communication frequencies across functions in a team. Control room technicians (CRTs), for instance, received a large number of calls 
from onshore, not all of them directly related to their own work. As one CRT remarked:

"[The central control room] is the telecom exchange as well for all the calls from the beach. If they don't know the direct dial number, they come straight in here, 'oh, I need to speak to such and such'."

Onshore planners and some onshore managers, on the other hand, very rarely contacted offshore, unless unexpected situations occurred:

"It can be a high frequency of interaction with the offshore guys. It just depends what the issue is. You know, I've probably had half a dozen emails a day in the last two days from the offshore team leader on a particular issue. So there is a fair bit of communication there. Then it might dry up and there'll be nothing for a week or so, and then there might be a lot again." [onshore technical authority]

Apart from regular communication in meetings, the amount of contacts between subgroups seemed thus largely driven by events offshore that required input or support from the onshore office. Prior to the implementation of the new ICT, the majority of communication between office and rig was carried out by phone or email. Onshore engineers generally seemed to prefer the use of phone for quick updates on information. One of the reasons given for this preference was the habit of offshore staff to ignore emails. Offshore seemed to prefer the use of emails, partly because onshore engineers were often not available at their desks, but also to document requests from onshore:

"We do use emails all the time because I kind of like to confirm what we discussed. So if we have a meeting and take some actions, then we file an email with the actions, so they are written down, kind of black and white. Similarly, if we set up like a program to do some tests, again we discuss, and then someone would send an email with all of the steps to make sure we captured everything and there isn't any room for interpretation." [offshore manager]

For the exchange of information between onshore and offshore before the implementation of new ICT capabilities, information such as pictures, spreadsheets, or presentation slides were distributed attached to emails. Both sides had perceived this as highly inefficient, but the lack of alternatives made this a common practice. The implementation of $\mathrm{VC}$ and desktop-sharing opened new ways of distributing information. For example, instead of sending photos, offshore now showed small pieces of faulty equipment directly on the VC.

The use of spreadsheet attachments also decreased due to the easier access to process and plant data in the onshore office, as the new data screens in the team areas conveniently showed the same information in a continuously updated way. The screens dramatically improved the accessibility of this type of information and allowed all team members, independent of their job 
function, to monitor trends and status information. Initially, the new data screens received somewhat mixed reactions. While some onshore engineers immediately perceived them as valuable for a better awareness of the present plant and process status, others such as this maintenance engineer were more skeptical: "There's no real-time data that we in the maintenance group would require". Asked before the actual implementation, whether they expected the data screens to be helpful for the coordination with onshore, offshore technicians and managers expressed the hope that the data screens would help prevent misunderstandings and support complex discussions:

“Once they've got that access and got that knowledge, then yes, I suppose it is [helpful]. When you can talk to them and say, 'this is what I'm looking at', and you're looking at it as well; but when you are trying to explain something that they can't see, then you're not really benefiting." [offshore team leader].

Based on our observations, onshore engineers used the data screens most often for a quick glance to get a general impression of the plant and production status. However, the following comment by a control room technicians suggest that the data screens were not always used to their full potential:

"We still get bizarre requests where somebody [from onshore] will phone up and say. 'what's the pressure, what's the temperature of components?' Why phone the control room? [...] Start looking at the data, which they can get on the screen." [control room technician]

$\mathrm{VC}$ or phone conversations were frequently accompanied by desktop-sharing software with the capability to display and manipulate the same data on screens onshore and offshore. Before, discussions of presentations were either done with separate paper versions or on independent computers, each side flipping through the slides at their own pace. Using desktop-sharing, slides were now available in the office and on the rig simultaneously. Not surprisingly, this practice made it easier for both subgroups to follow the flow of the presentation and reduced the number of misunderstandings as to what slide, picture, table, etc. the presenter was referring to.

Over time, the new ICT replaced some of the traditional media and changed interaction patterns. Most markedly, the video-links replaced a considerable number of phone calls and nearly all interactions via audio-conferencing. At the beginning, offshore staff was reluctant to use or allow the use of the continuous videoconferencing links. The video-connections into the control room were frequently seen as intrusive and a risk to the independence of their offshore working life-style. CRTs further perceived it as added pressure from onshore ("Ijust don't like it. I mean, maybe it's a bit of added pressure if somebody is watching you"). Especially in the early stages after the implementation of video-links, offshore technicians reacted by placing coffee cups and hardhats on cameras or by pointing the cameras to ceilings or 
corners. Overall, acceptance of the video-links seemed to be higher onshore than offshore, yet as this comment shows by no means universal:

"Obviously there's a feeling of invasion of your privacy. And I know, sitting there at this end, when the camera is on at the side, you hear the ring; you know somebody is ringing up. You brace, you watch the camera coming round on you. It's a bit spooky. You know, you think, 'oh my god, I have to be on my best behavior now, you know, stop picking my nose-'." [onshore engineer]

After some months acceptance increased and in most teams video-links were used almost routinely instead of phones. On several occasions we could even observe purely social contacts between onshore engineers and technicians or offshore managers, for instance, when CRTs presented their newest T-shirts to the onshore office, offshore managers placed playful orders for chocolate cookies, or onshore engineers relayed recent travel experiences abroad. This type of personal relationships had not existed before the implementation of VC. As one onshore engineer remarked, "some of the guys that I've hardly ever spoken to before I'm now chatting away like we're best of friends". On one occasion the combination of VC and netmeeting was also used to conduct training sessions for offshore staff. Previously trainers either had to travel offshore or offshore staff had to come into the office to receive the training. Using the VC-connections, offshore staff now also had the opportunity to directly participate in company town hall meetings.

Not all teams accepted the new ICT with equal fervor and consequence. Especially, the extent of VC-use varied considerably across teams. The majority of teams used the VC-links to the control and meeting rooms offshore as a replacement for phone, email, and audio-conferencing. During the time of our study, two teams used VC only for formally scheduled meetings due to low acceptance by both onshore and offshore staff. On several occasions teams discontinued the use of the VC-links for the duration of a shift, because the new shift "did not like the camera". In these teams, offshore technicians still frequently requested that information or instructions for activities like tests, chemical sampling, or changes to plant configurations were sent by email. These emails seemed to act as safeguards against their supervisors, so that in case of conflicts the technicians would be able to demonstrate that they had acted on the explicit instruction of onshore engineers. The strong offshore hierarchy here seemed to counteract the opportunity for closer contacts and integration of processes at the lower levels of the organization.

Standard mail between onshore and offshore was used primarily for documents that needed signing or company communications such as internal newsletters. This way of communication was comparatively slow, as all mail had to be sent by helicopter, which usually happened on shift change days once a week. We do not have any indications on how frequently standard mail was used, but as neither onshore nor offshore staff mentioned standard mail when asked for ways of communicating or exchanging information, we can assume that it was not a prominent medium. 
An overview of the media available in our sample, primary reasons for media choices based on self-reports and observations, and average usage frequencies as reported in the interviews can be found in Table 4.

\subsection{Coordination requirements and technology effects - illustration for critical activities}

Coordination of processes and tasks between office and rig had to be managed on a continuous basis to achieve the overall team goal: maximum production under safe conditions. As all interactions were of necessity mediated by media, their capabilities influenced the ability of team members to coordinate. Specific to our sample was that teams were able to use a complex mix of ICT, which either complemented (e. g., VC, desktop-sharing) or competed (e. g., AC, VC, phone) with each other.

In the following sections, we describe our findings on the use and effects of ICT with respect to the five critical team activities, i. e., planning, monitoring, troubleshooting, informing/reporting, and executing. These activities were chosen, because they represent a range of tasks from primarily onshore to primarily offshore responsibilities, as well as instances of cyclical, ongoing, and sporadic coordination.

\subsubsection{Planning}

Planning can be considered one of the most critical activities for oil production teams. Planning encompassed everything from the forecast of production numbers, the long-term preparation of equipment and plant maintenance to the logistical steps of getting people and equipment on and off the platform. Because of the remoteness of offshore platforms and the restricted space to house people and store equipment, every transfer of personnel and goods had to be planned minutely down to the number of available seats in a helicopter and the number of free beds on the rig. The main planning responsibility lay with onshore, and the process was optimally seen as a one-way process from the office to the rig:

"Onshore is really the decision part. It's like planning the strategy, what are we going to do, and how are we going to do it. Offshore, theoretically, is pure execution. It's just, 'do what onshore says.'” [offshore engineer]

Onshore engineers were responsible for the planning of individual activities and the preparation of work packs. The grouping and scheduling of activities was then done by specialized onshore planners. Planning progressed from a first high-level plan which indicated the main activities in the coming eight quarters to ever more detailed plans looking ahead for twelve weeks, six weeks, and finally two weeks. Each of the activities in these consecutive plans needed to comply with so-called gate criteria, before it could progress into the next planning stage. Planners had to make sure, for instance, that materials were ordered and available twelve weeks ahead of execution. Six weeks before execution the materials needed to be available for transport to the platform, and two weeks before execution they needed to be either on 
Table 4. Media use in the sample.

Medium $\quad$ Observed and reported reasons $\quad$ Reported frequencies

\begin{tabular}{|c|c|c|}
\hline \multicolumn{3}{|c|}{ ASYNCHRONOUS MEDIA } \\
\hline Reports & $\begin{array}{l}\text { Documentation of activities and } \\
\text { status; common ground for } \\
\text { group meetings }\end{array}$ & $\geq 1 /$ day \\
\hline Email & $\begin{array}{l}\text { Follow-up on phone calls or if } \\
\text { not available by phone; } \\
\text { documentation of results; more } \\
\text { complex requests; contact to } \\
\text { unfamiliar people }\end{array}$ & $\begin{array}{l}\text { 1-250/week (depending on job } \\
\text { function and situation) }\end{array}$ \\
\hline $\begin{array}{l}\text { Email attachments } \\
\text { (pictures, slides, etc.) }\end{array}$ & $\begin{array}{l}\text { Preparation for group meetings; } \\
\text { documentation; common ground } \\
\text { for trouble-shooting (e. g., pictures } \\
\text { of failed equipment); exchange } \\
\text { of information such as plans, } \\
\text { data dumps of offshore real-time } \\
\text { data, drawings }\end{array}$ & Depending on the situation \\
\hline Planning software & $\begin{array}{l}\text { Detailing and scheduling of } \\
\text { offshore activities }\end{array}$ & Continuous for planners \\
\hline Standard mail & $\begin{array}{l}\text { Exchange of documents that } \\
\text { needed signing; internal } \\
\text { company communications }\end{array}$ & [not reported] \\
\hline \multicolumn{3}{|c|}{ SYNCHRONOUS MEDIA } \\
\hline Phone & $\begin{array}{l}\text { If information is needed fast or } \\
\text { information is of low complexity; } \\
\text { quick updates; short requests }\end{array}$ & $\begin{array}{l}\text { 1-100/week (depending on job } \\
\text { function and situation) }\end{array}$ \\
\hline Audio-conferencing & $\begin{array}{l}\text { Group meetings (usually replaced } \\
\text { by VC where available) }\end{array}$ & Approx. 6/week \\
\hline Video-conferencing & $\begin{array}{l}\text { Group meetings; replacement } \\
\text { for phone, mail, and AC }\end{array}$ & $\begin{array}{l}\text { In most teams continuous use } \\
\text { through 'always-on' VC- } \\
\text { links; } \\
\text { in few teams only on an } \\
\text { as-needed-basis for meetings } \\
\text { and one-on-one conversations }\end{array}$ \\
\hline Desktop-sharing & $\begin{array}{l}\text { Access to the same information at } \\
\text { the same time in both locations } \\
\text { during meetings for easier reference } \\
\text { (e. g., use of mouse pointers to } \\
\text { details, pacing of slides); } \\
\text { manipulation of information } \\
\text { 'on-line' for faster decisions } \\
\text { and documentation }\end{array}$ & Depending on situation \\
\hline Plant data and trends & $\begin{array}{l}\text { Monitoring (offshore); basis for } \\
\text { planning decisions (onshore); } \\
\text { early warning of potential } \\
\text { problems offshore (onshore) }\end{array}$ & $\begin{array}{l}\text { Offshore constant; onshore } \\
\text { depending on availability and } \\
\text { job function }\end{array}$ \\
\hline
\end{tabular}


the platform or arriving shortly. Similar gate criteria existed also for all other aspects of a task, such as financial approval, availability of personnel, or special tools. An activity was only moved to the next planning phase if all requirements were fulfilled at that gate, otherwise the activity had to be rescheduled to a later date. The final plan listed every type of material, equipment, number and type of personnel, duration of the job, as well as related activities such as local isolations or scaffolding required for its execution. This two-week plan was prepared by the onshore planner, sent offshore for review and if accepted, finalized and send back to offshore for execution. These plans were generally sent as documents attached to emails, in which offshore managers "red-lined" problematic activities. The reviewed document was then sent per email back to the planner.

The observed teams further conducted regular planning meetings, usually once a week, in which the six week plan was discussed between managers and engineers onshore, and managers offshore. In these discussions offshore provided input on possible constraints, for instance, whether the required technicians were available for the scheduled shift, as well as suggestions on the clustering of related tasks. While the planning and scheduling was driven by onshore, onshore did not "micromanage" offshore jobs:

"Offshore is only responsible for the six week window, but there are processes to take place for any activity in there that needs to be scheduled. Now, if they are talking about a piece of work that needs a guy or a couple of guys offshore that needs to be scheduled, that has implications for POB [personnel on board], the chopper seats, the materials, or the equipment when it's going to be shipped. That has implications, so there have to be conversations on that. But if we're talking about a $1 \mathrm{hr}$ job for a tech to go out and do something, that's completely on them. I'm not micro-managing right down to the tech, one-hour jobs. I'm sort of doing the higher level process and lining up the actual work with a block of time that somebody should be there." [onshore planner]

Plans frequently had to be changed on short notice due to unplanned events like sudden breakdowns of equipment or spells of bad weather that made the execution of outside work impossible. In an extreme case, bad winter weather prevent helicopters from landing on a production ship to bring in new staff and take people off; even boats were not able to land, so that instead of the usual fourteen days, offshore personnel were forced to stay on-board for over three weeks. In that time, not only food became sparse, but also electricity and materials. Moreover, tools, materials, and specialist vendors could not be brought offshore and most planned activities had to be put on hold until the weather cleared. The complexity of plan changes can be illustrated with this account of an onshore planner:

"You look at when that activity may have to happen, what's in there. Does anything need to move, has anything got to be rescheduled to allow that 
piece of work to happen? Then the discussions start, 'right, we can do that job; we need three mechanics to work on the process or the gas turbines. For this job here, we need mechanics, then we can't do this job and we need to reschedule that one to later. So maybe reschedule that a week back'. And then we got the whole process of telling the, saying to the vendor who was meant to come out at that point, 'sorry, that got put back for a week'. They may not have that guy for that week [...] It's always continuously moving. It's not something that's hard and fast, 'thank you very much', and walk away. It's continuous, every day, every day."

Although planning was such a critical activity, onshore as well as offshore personnel often questioned the efficiency of the process. The main problem for onshore engineers lay in the lacking knowledge of local constraints:

"You know, we can't see clashes of steelwork or metal work, pipe work. Plus they might not have someone in place to do the job. If I think, 'ah, it's going to take eight hours', then they say, 'ha, that's a three day job; two men for three days, not one guy for one day."' [onshore engineer]

Other challenges mentioned by offshore engineers and technicians were due to different priorities of onshore and offshore subgroups:

"At our level it's very, very difficult to try and communicate with them [onshore] [...] because they're busy, or what we're asking for is not in the priority list; they've got other challenging sort of projects going on." [offshore technician]

— and sometimes even wounded sensibilities:

"How are you, this young one, who's been online for three months, telling me how to change this part when I've done it twenty times?" [offshore engineer]

Using input from offshore to keep plans up-to-date with recent developments or prevent possible conflicts between tasks and resources required a considerable degree of interaction and information exchanges between subgroups. Traditional media like phone, email, reports, or audio-conferencing often were not able to provide sufficient support, mostly because information lacked the necessary detail (e. g., audio-conferencing) or timeliness (e. g., reports, email). The implementation of new media allowed a more inclusive approach to planning. Observations of teams showed that onshore engineers used the video-link to request input from CRTs and offshore managers on a spontaneous basis to clarify details in a plan.

$\mathrm{VC}$ was also used in the planning meetings together with a desktop-sharing tool. In these meetings, onshore and offshore subgroups viewed, discussed, and revised plans directly during the planning meetings. In this way, checks 
and fine-tuning were achieved in one session instead of a series of mails or calls, which tied down fewer resources for a shorter period of time. Moreover, since the VC-connections were located in the control room, planning meetings now also included technicians and control room operators. Before, such meetings had been restricted to management levels. For offshore personnel this was a clear benefit, because their point of view was integrated into the plans early on:

"Because from the onshore point of view, if you think of it, they take more the project, long-term point of view and that sort of stuff, 'so what do we need to do to fit into that?' But as from the offshore point of view, we take more day-to-day, what we need to do today to get it going. And then the CRTs, the operator point of view, they think about how practical it is to execute those plans. So it's nice when we have everybody's input." [offshore engineer]

Overall, our observations indicated that offshore personnel became more closely involved in the planning process, bridging the strict divide of planning and execution roles. This shift generally led to a higher accuracy of plans and less re-planning.

\subsubsection{Monitoring}

Oil production is a continuous process with potential risks for personnel, equipment, and environment. The main activity for control room technicians (CRTs) offshore was therefore the monitoring of processes on the plant. CRTs were located in the control room as the 'heart and brain' of the platform, from where they controlled the electronic and mechanical systems such as valves, pumps, flow rates, fire alarm systems, or fluid pressures and temperatures. Their main tasks were to monitor and control the status of the plant, to react to any changes or system alarms, and to implement production strategies agreed between onshore and offshore. CRTs were ultimately responsible for the first response to problems, which required an in-depth understanding of the system and quick decisions. Monitoring was the sole responsibility of CRTs; other offshore personnel or onshore engineers were not involved in the immediate monitoring process.

Due to this strict role separation, onshore engineers in the traditional setting had no direct access to real-time process data. If requested, offshore staff sent snapshots of real-time data as spreadsheets:

"Real real-time data they can [get], but that's our decision. But what we do, we print off a graph or we do a data dump and send it to them, so they can look at it." [offshore installation manager]

Data-bases with some parameters had been available, but were seldom used because onshore engineers perceived the access as cumbersome and of little 
relevance for most jobs. With the installation of the large data screens in the onshore team areas real-time data became easier available, and onshore engineers used these screens to monitor developments of their platform. The main benefit of the screens for onshore engineers was a better understanding of the present production and plant status:

"You can see what the state of the plant is; and the moment in time you see it go down, you think 'oh, what's happening?' [...] So in terms of being aware of how the plant is running and the impact, I think, it's great."

This better awareness of the plant status in the onshore office also reduced the need to contact offshore staff for updates or detailed information, and thus eliminated distractions and reduced the workload for CRTs.

With the data screens, onshore engineers slipped into a kind of secondary monitoring role scanning the information for unusual patterns and signs for potential problems. Still, monitoring onshore and offshore retained very different functions and criticality. While CRTs required second-by-second data to control the live system, onshore engineers focused on trends and longer-term developments to forestall negative developments (e. g., equipment breakdowns) or to chart possible improvements to the plant. Offshore monitoring can thus be seen as part of a 'fast feedback loop' (seconds to minutes) to catch immediate events, while onshore represented an outer, slower feedback loop (hours to days). The delay between the two feedback loops was part of the different roles of onshore and offshore staff in the operation process. The availability and quality of data onshore, however, impacted the possible speed of reactions by onshore to actual or potential problems offshore. The immediate accessibility of offshore data effectively drew onshore closer into the fast feedback loop:

"We already had a portion of real time data that was coming into the office. We probably weren't using it. The difference with having the [new ICT] was the data was there in the past, but we didn't have the screens around us to project the data up, which would provoke a conversation; now we do. So the data is now there, we'll try to have a monitor, which will have the minute by minute production from the field and minute by minute injection rates, and so having that, took away having to pull any other type of data up. And having it right in front of you, that allows us to- 'wait!'. It just raises questions, 'oh, why did that happen?', and, 'well, lets look into it'. It provokes an investigation rather than not noticing until weeks time, when it comes up in a summarized report or we're even missing it." [onshore manager]

Onshore engineers and managers were generally positive about the increased possibility to monitor plant processes from the office, because it gave them a better awareness of the plant and production status and an earlier indication of potential problems. However, observations suggested a more problematic aspect 
of this secondary monitoring role, namely the blurring of the original division of onshore and offshore roles. As one onshore manager explained, "the primary focus is strategic for onshore". With the availability of real-time data and the easier access to the control room, onshore engineers were now drawn closer into the day-to-day issues on the platform with the danger of loosing their longerterm, strategic focus:

"[Onshore] you're supporting the frontline for sure, but that's a longer time frame. I mean, the guys offshore, the mechies and techies and stuff offshore don't need any help changing transmitters. They don't even want to talk about it. That's their job. But I just see it. They [onshore] get sucked-, they have just been sucked into that." [onshore manager]

The new ICT thus seemed to be a two-edged sword for onshore staff. While on the one hand it provided onshore engineers with a better awareness of processes and the ability to spot potential problems earlier, it also seemed to invite a move into a more tactical, short-term role. This blurring of roles could leave a gap with respect to longer-term, more strategic decisions, moving team activities from a pro-active process driven by onshore strategy to a more reactive stance driven by demands and requirements offshore. Based on our observations most teams seemed able to retain the separation between a longer- and short-term focus, although several onshore engineers voiced concerns that the increased demands by offshore left insufficient time for the longer-term aspects of their jobs. Especially, higher than normal workloads or a series of unexpected events could considerably increase the pressure on onshore staff to drift into a short-term support role.

\subsubsection{Trouble-shooting}

The two major types of problems requiring onshore-offshore coordination were production losses and safety-critical events with the potential to endanger plant, personnel, or environment. Offshore participants often described themselves as "the first line of defense and the first line of attack". They not only carried the personal risks in case of major incidents, but direct intervention and access to first-hand information on incidents were only possible on the rig itself. The majority of problems were handled directly by offshore staff and then reported at the next regular team meeting. As these comments suggest, both subgroups accepted this as an efficient way to deal with minor problems:

"One of the machines shut down, one of the compressors. It was a water cooling system for the lubricating oil and the lubricating oil went too hot, so it shut down and they found out it was a pressure control valve that had failed. And they [offshore] then made the decision by themselves to take the one from a machine that was down and they would scavenge it and just put 
it in. They didn't have to wait and say, 'it's gone down, can you get a spare for us?' They took that by themselves, and therefore they came back faster then they would otherwise have done." [onshore engineer]

"We are pretty self-sufficient in quite a lot of things. If we have a problem here, then we try to solve it ourselves first, do what we need to do out here. [...] [Our technicians] can telephone various vendors, if we need any spare parts. They can purchase material. They can order those sort of stuff themselves. [...] If we have a problem, we can't solve here, we tend to give the engineers a telephone call." [offshore manager]

As this last comment indicates, onshore involvement became necessary when offshore staff was not able to diagnose the problem or when solutions had to be checked for compliance with technical standards or industry procedures.

The main problem for effective cooperation in trouble-shooting was for onshore staff to obtain timely information that a problem had occurred. With traditional media like phone or email, onshore personnel had to trust their offshore colleagues to contact them, as this was the only way to know an unexpected event had happened. The lacking transparency at times led to a clash of expectations between the selfproclaimed "self-sufficiency" of offshore and the desire of onshore engineers to be informed of events or involved in problem solutions:

"You go in on a Wednesday morning and you find out that something happened on Tuesday morning and they never told you. They say, 'well, we rang and you weren't there. We tried to call such and such'. And you don't really know if they have or not or if they just kind of said, 'oh, we'll just make a decision ourselves'. [onshore engineer]

Another problem was to obtain accurate and detailed information on the event to create a common understanding of the problem, as well as a shared understanding of possible solutions. In the traditional setting, offshore staff frequently attached photos, drawings, or test results to emails, which were then discussed by phone or audio-conferencing:

"I could get a phone call right now where there is a problem with a valve, for example. Now, the guy over the phone, he's seeing the specific problem right in front of him, so he knows roughly what it is or what it might be. So he then picks up the phone-. There are three choices. He drops an email, trying to describe the problem or he can pick up the phone and try to explain the problem. More often than not, from his initial phone call, I will have two, three, four more phone call between us. And maybe I have specific questions, is it this or really this. To the point where, email is more advanced these days, so the guy can take a drawing and scan it or make comments on the drawing and send it. And then again, that will involve more phone calls to discuss this drawing. And that is in general how it works." [onshore engineer] 
Although solutions for complex problems were driven by onshore, both sides agreed that engineering knowledge and on-site knowledge had to be integrated to find the best possible solution:

"Offshore tend to have knowledge and understanding, but in a different way. So they know if they turn valve $A, B$ happens, but they don't always know why. Whereas onshore, you tend to know what should happen and what might happen; if you do A then B will happen, but also C, D and E. And what you need to do is get both parties talking to each other and understanding that one group doesn 't have all the knowledge. You actually need to marry both of them together to make the right decision" [onshore manager]

Our observations indicated that this process when based on phone, email, and audio-conferencing could lead to drawn out discussions and was fraught with misunderstandings, which can be problematic especially in time- and safety-critical situations. The new ICT supported trouble-shooting in two ways. The data-screens in the team areas onshore showed dips in production or unusual patterns in equipment parameters. Instead of having to wait for a phone call or email from offshore, onshore engineers could thus register unusual events as they happened. While not of immediate use for the analysis of the problem, the data screens alerted onshore faster of potential problems and in this way reduced the likelihood of problems going unnoticed. The introduction of video-conferencing further improved the speed and accuracy of problem-solving by supporting visual information like hand gestures or presentation of objects, as well as increasing the access to onshore expertise:

"You try to explain locations of things [...] 'It comes down from the deck like that and it comes across like this and it's supported under there like that.' [moves hands to demonstrate]. You can do that kind of thing and it makes it a lot easier." [offshore manager]

"The guys in the control room can walk around and see the folk sat there and say, 'We just had an alarm on such and such and what should we do?' And they're able to deal with it instantly. So they've suddenly got a room full of experts, they can call in for help." [onshore engineer]

The benefit this new technology could have for the speed of trouble-shooting can be demonstrated by the following example:

"The classic example [...] was when the guys offshore used to do some oil sampling of the main generation turbines, and the sample when it is supposed to be a nice light, like a lager color, it came out like Guinness black. So they immediately ran down the stairs, pointed it up the screen and said, 'look, that's the sample'; and we said, 'shut the turbine down'. Now and that was a decision made there and then. It wasn't a case of, 'you know, oh, is it that bad? Send it in for analysis. When the analysis is done we're 
going to worry about it'. So where it could have been three or four days delay, could have been a train wreck in the equipment [...] it was right up at the screen, 'this is how it should look like, this is what it does look like' 'Ah, we got a problem. Shut it down'.' [onshore engineer]

Despite such clear advantages, offshore technicians and managers felt that the greater visibility of problems and the presence of onshore engineers through video-links also had its negative aspects, primarily an increased pressure for CRTs:

"The last thing [the CRTS] want is somebody standing over their shoulder. And basically that screen at that period would be somebody looking over their shoulder or wondering what's going on; or they [onshore] would [...] say, 'there's been a trip on [the platform]'. Somebody would phone me." [offshore installation manager]

Similar to monitoring, the added visibility and copresence between subgroups had thus positive, as well as negative aspects. On the one hand, increased visibility of problems improved the efficiency of coordination in trouble-shooting activities. On the other hand, the lacking visibility had provided an effective safeguard against 'meddling' or 'over-involvement' by onshore. Usually, smaller problems were handled directly by offshore staff often without onshore staff knowing that a problem had occurred. Due to the implementation of real-time data screens and continuous video-links, onshore engineers now were also aware of smaller problems. The new ICT thus changed the traditional escalation strategy from offshore to onshore, with the consequence that onshore engineers were more often drawn into resolving minor issues and took part in reactive fire-fighting. Again, similar to monitoring, the new media encouraged a blurring of the traditional onshore and offshore roles.

\subsubsection{Informing/reporting}

The geographical distance and low visibility of processes made the task of informing and reporting probably the most important activity for subgroup coordination in production teams. Without proper information on the present production, type and dates of planned shipments, weather developments, equipment failures, upcoming maintenance work, or available personnel on board, coordination would operate in the void.

The main topics on which onshore staff needed information and reports from offshore were updates on production numbers, tasks executed in the last $24 \mathrm{hrs}$ and planned tasks for the coming day, information on health and safety, weather, logistics, as well as sudden changes in the operation of the plant, breakdowns of equipment, and changes in the plan due to unexpected events. Information from onshore to offshore was needed on topics like production forecasts, planning decisions, or changes in agreed plans. 
Traditionally the most important activity for the exchange of information and updates on developments offshore over the last $24 \mathrm{hrs}$ were morning meetings. Before the implementation of $\mathrm{VC}$ these meetings were conducted over audio-conferencing between onshore engineers and management on the one side and offshore management on the other. The frequency of these morning meetings varied across teams from every day (Monday to Friday) to three times a week. In these meetings also plans for the day and possible challenges to existing plans were discussed. In the traditional setting, these morning reports were often the only regular contacts between onshore and offshore staff. Over the week additional meetings took place for specific topics like maintenance planning, production planning, logistics, or health and safety, or environmental issues.

Outside of meetings, information requests by either onshore or offshore staff were sent by email or discussed over phone. The difficulty of relaying information in a fast and efficient way between onshore and offshore using traditional media may be judged by this report of an onshore engineer:

"It can be as bad as having to walk several hundred yards to a noisy telephone booth, ring onshore, they get the support engineer's voice mail because he is away in a meeting. He then leaves a message, goes back to the work site, the engineer comes back, calls the platform, can't get the person; they put a pager out for him. Now, the guy on-site probably won't hear that pager, because it is noisy and if he does hear the pager, he has to go and find a phone to call back. At this point, [the onshore support engineer] has gone to another meeting. It is like ships passing in the night."

The difficulty of getting hold of onshore engineers was the most frequent complaint by offshore managers and technicians. The continuous video-links improved this situation dramatically, as now offshore personnel could easily oversee the team area to check whether a person was available. Videoconferencing also allowed more direct conversations between subgroups, which both sides perceived as a welcome time saver:

"It's stopped a lot of the three-way communication. So it's stopped [the onshore engineer] calling me, me going to the CRT, the CRT telling me they can't do it and then me going back to [the onshore engineer], 'they say they can't do it'. So now we have the meetings, where we have basically all three of us to make the decisions, and everybody puts in." [offshore engineer]

Since the continuous video-links allowed easier interactions during the rest of the day, many of the formal meetings not only became shorter and more focused, some teams also reduced the total amount of meetings, as onshore staff tended to be informed of activities and developments on an ongoing basis. Because the VCfacilities were located in the control room, technicians and CRTs were now included more frequently in discussions, which increased the spread and flow of 
information between subgroups. At the same time, onshore managers saw less need to be present in meeting between subgroups:

"As a team leader you would be tied up in meeting after meeting after meeting, and a lot of it was repetitive to be honest. So now that the meetings are running well, team leaders tend not to go to a lot of the meetings. [...] And it's not because of lack of interest. It's there's no need. [...] It's freed up a bit more time for team leaders to do some thinking time." [onshore manager]

The new media capabilities added visibility and cotemporality for personal communications, as well as data. Over time this achieved a better awareness between members of onshore and offshore on multiple levels: in the short-term on present activities and work load; in the mid and longterm a better understanding and appreciation of roles, responsibilities, and systems. Most problematic in the traditional setting was in the eyes of onshore engineers the lacking awareness of production and plant status and the low transparency of processes offshore ("The only way we could find out if a piece of plant was online was to call the control room on the phone and ask them"). Onshore engineers therefore greeted the implementation of the data screens as a way to increase their general awareness of the plant status. As discussed above, onshore engineers generally did not use the screens for in-depth insights into the running of the plant, but to obtain quick updates on the plant and process status. The availability of real-time data further reduced the need to call the control room offshore for routine information, which reduced the amount of disruptions for CRTs throughout the day.

Overall, the implementation of new ICT seemed to have made reporting and informing between subgroups easier and more efficient; the main benefits being the better access to expertise in either subgroup, less time wasted in trying to get hold of people, and more focused, shorter interactions. Generally, informing and reporting became less sporadic and less formal. Instead of formally scheduled meetings, contacts between subgroups were spread throughout the day instigated more by immediate needs for information:

"Nine times out of ten the guys would phone you first thing in the morning, and you would have a chat what they would do offshore, what support they were needing, etc. And that would be it; you would only speak to one mechy or maybe two mechies, depending who's on shift. Now, they'll come in, they'll have a chat with you in the morning, and then lunchtime they would come in with some of the vendors that may have a question. And rather than them being the conduit where the vendor has asked them the question, they've posed me the question, I reply to them and them going back to the vendor, the vendor is there already. And the guys offshore regularly take in the vendors, we've got this problem or we just want a bit of clarification on certain things. So the guys are on the VT, oh, I would say, three, four, maybe five time a day, while before you might only have that one phone call in the morning." [onshore engineer] 


\subsubsection{Execution}

The direct execution in terms of daily oil production and maintenance of the installation is by necessity an offshore task, and in general offshore personnel tended to prefer as little involvement by onshore personnel as possible:

"We're always working towards a plan. We know on a day-to-day basis what work is coming up and you mainly only get personally involved with the beach if something goes wrong." [offshore technician]

Execution of tasks encompassed maintenance work by technicians, monitoring and controlling of the platform, as well as changes to the well configuration by CRTs to optimize or restore production. Execution was considered a pure offshore task. For this reason, traditionally the onshore subgroup had only very restricted access to real-time information from offshore.

As already discussed in other activities, the implementation of the additional ICT capabilities increased awareness of plant status and improved access to offshore personnel. This meant that onshore engineers and managers were better informed about activities at the remote site and over time obtained a better understanding of equipment and well behaviors. Due to the direct video-link into the control room production engineers were more frequently and directly involved in the fine-tuning of equipment for the optimization of production. Where before engineers would have sent a document with details on the requested changes by email, often followed up by phone calls or other emails to clarify and revise procedures, procedures were now discussed directly with the control room operator on the board.

Besides this more active role of onshore staff in influencing well settings, improved relationships and trust between subgroups also led to a tendency to relax control:

"I just flag up this job saying 'needs to be done some time in the next three months'. Whether it is then today or in two and a half months time doesn't matter [...] so they can have the freedom to manage some of the tasks offshore. We don't need to have that control as well." [onshore engineer]

Yet, our observations on execution also highlighted another potentially problematic aspect of the technological change. Work processes offshore were highly scripted and proceduralized, in that every activity had to be checked and signed-off by supervisors and entered into a planning system to prevent potentially dangerous overlaps between tasks. For this reason all requests were usually first sent to offshore managers, who then relayed these requests to the appropriate technicians for execution. Especially offshore managers feared that the easier access to lower levels of the organization could lead to a slipping of control on activities offshore:

“The 'always on' thing is great. I wouldn't take anything away from that, but there needs to be clear boundaries as to what decision can be made. 
[...] My worry is that if you don't set that boundary up, we could just sit up here, unless we've got a three-way [VC], we could just sit up here, go downstairs and the whole world has changed." [offshore manager]

If not managed correctly the increasing involvement of onshore in requesting and guiding activities at the technician level could thus be a potential danger for the integrity of the existing control system.

\section{Discussion}

In this study we tried to gather first insights into how changes in ICT influence everyday work processes in ongoing distributed cooperation. For this purpose, we analyzed cooperation processes in offshore oil production teams and the impact of changing media capabilities on subgroup cooperation. The tasks of onshore and offshore subgroups in production teams were found to be closely interlinked and consequently both groups had to rely on tight coordination to accomplish their common goal, i. e., maximum oil and gas production under safe conditions. Although type and degree of interdependencies varied across the main activities, the performance of one subgroup depended very much on the performance of the other, indicating high task interdependency (Thompson 1967; Van der Vegt and Janssen 2003). Due to the inherent geographical separation this interdependence had to be managed with sole reliance on communication and information technologies to support coordination, as well as to mitigate the dynamic nature and potential risks of the team task.

Under normal conditions, i. e., undisturbed plant operations, the respective roles and division of labor between onshore and offshore were well established and did not require much negotiation. Differences in terms of primary tasks, work schedules, or access to plant and information were well known and integrated into the normal work process due to a long common history of remote cooperation. Yet, the existing processes and routines had been developed based on traditional media capabilities (phone, email, mail, audio-conferencing, planning systems), which provided little opportunity for direct continuous interaction between subgroups.

As we have seen in our findings for individual team activities, the new ICT capabilities shifted the clear boundaries between established responsibilities, such as a higher degree of offshore involvement in planning or a changing role of onshore in monitoring and trouble-shooting. Although the main responsibilities did not change, over time the division of 'planning' and 'doing' between subgroups became less strict. Traditionally, subgroups tended to act as "segregated territories" (Clement and Wagner 1995) in which the combination of homogeneity in local groups and heterogeneity of distanced groups hampered the establishment of common interpretations of information and situations. The implementation of $\mathrm{VC}$ and better access to data increased the ability to establish shared interpretations and understanding, which could considerably increase the speed of reactions in sporadic activities like trouble-shooting. Overall, the better 
awareness decreased the need for direct contact for routine information, while the VC-links facilitated contacts for non-routine information. Observing teams over twelve months, these media further seemed to help in removing negative effects of remoteness also in less tangible areas, e. g., by increasing the mutual understanding of each others' roles and capabilities and a better acceptance of potential conflicts over priorities.

The new tools also helped to increase social interactions, as well as better awareness on "who is around" (social awareness), "what is happening" (action awareness), and "how are things going" (activity awareness) (Carroll et al. 2003). With traditional media, this type of information was nearly impossible to obtain, leading to a state of team opacity related to coordination problems and failures (Fiore et al. 2003). As work in the aviation industry and offshore oil drilling demonstrates, situational awareness and understanding of situations play an important role in the avoidance of accidents (Jones and Endsley 1996; Sneddon et al. 2006). As Heyer (2009) observed in his ethnographic study in an oil and gas refinery, engineers were conscious about their lower level of awareness about details on the plant compared to field operators with continuous access. In their opinion, video-links or reports could not replace getting a first hand 'personal impression' of problems. Our onshore engineers felt the same way, but the geographical distance between onshore offshore and rig, as well as the logistical hassles involved in sending people offshore makes physical access to the plant much more difficult than for land-based refineries. Onshore engineers still went offshore in case of more severe problems, but compared to the traditional setting the additional ICT made these visits less frequent. Also, while visits to the rig may provide onshore engineers with a 'snap-shot' of processes offshore, the new ICT actually helped both subgroups to develop a more realistic picture of work processes at the 'other end' in the long-term.

The impact of the new ICT did not lead to a radical change in team coordination, but rather to the modification and adaptation of existing routines. We can therefore speak of a transformation of capabilities characterized by the "integration of new routines with carryover of existing routines" (Lavie 2006, p. 160). The additional ICT did not so much replace, but offer alternatives to existing media for better interaction and task support. These developments were frequently experienced as a positive change from the former situation, as it made interactions smoother and more efficient. Over time, decision making processes involved more lower levels of the organization and reduced the transfer of information via managers, which increased efficiency of processes and decreased the involvement of managers in day-to-day tasks. However, as highlighted in the sections on execution, monitoring, and trouble-shooting, this development can also be problematic. Shifting the existing boundaries between planning and execution, and moving decision from managers to the 'shop floor' could lead to a situation in which the oversight of activities or developments becomes lost. For this reason Johnsen et al. (2007) actually argue that "increased connectivity and human collaboration in remote operations have significantly enhanced the risks to safety and security" in oil and gas production operations (p. 83). 
Overall, we identified three main challenges due to the changes in ICT capabilities in our sample: a) the blurring of the traditional subgroup roles of 'planning' versus 'execution', b) the loss of the longer-term, strategic focus for the team, as onshore became more involved in day-to-day activities offshore, and c) the loss of oversight for managers. These problems were perceived by onshore as well as offshore personnel, but we are not aware of any direct interventions to manage the potential risks involved in these shifts. Generally, risks were mitigated by strict rules and guidelines, i. e., a high 'scriptedness' of processes, specifically in the planning and execution of work, but it is not clear whether the existence of these guidelines and procedures will be sufficient to attenuate all potential negative effects. The existing rules and procedures, which had been developed based on the traditional capabilities for cooperation, were called into question by the newer media capabilities. For instance, the traditionally strongly hierarchical communication - from onshore engineers to onshore management to offshore management to offshore technicians-was rendered obsolete by the implementation of continuous video-links between onshore engineers and offshore technicians. While the organization overtly promoted this development, the consequences of these changes were not directly addressed.

The company-wide ICT implementation aimed at a 're-alignment' of onshore and offshore subgroups. Yet, it seems that the long-term consequences of closer onshoreoffshore coordination were not fully understood, and even less anticipated. The implementation of ICT had been announced as a means to improve support for offshore processes. Initial reactions by the majority of offshore personnel made clear, however, that this group perceived the initiative as a way to increase onshore control. The implementation thus infringed on implicit or explicit agreements with respect to onshore and offshore responsibilities and roles. As some offshore personnel pointed out, increased contact from onshore defeated the purpose of working offshore as a conscious decision to become 'unreachable' and independent. The psychological contract for these individuals had suddenly changed, which in some cases resulted in confusion and resentment. The initial rejection of the VC-links (e. g., putting hard hats or coffee cups over cameras, or pointing them to the ceiling and corners) can be understood in these terms. After some months the majority of onshore and offshore personnel seemed to have accepted the change towards the new technologies, and onshore and offshore subgroups developed usage routines for the new capabilities. The comparatively smooth transition may be due to the incremental nature of the changes, as well as the feeling that these technologies were unavoidable and part of "the future". Positive experiences such as faster problem identification or easier solution to operational problems further helped to increase acceptance.

\subsection{Considerations on technology design}

A major challenge in supporting distributed teams in the oil and gas production lies in the disparate requirements in terms of information and data between the 
two subgroups. Responsibilities for the nine primary tasks were not uniform, and accordingly the type of information needed by onshore and offshore staff varied considerably. At the same time the high task interdependency required continuous awareness of states and activities. During normal operations both subgroups based their work on the same general information, but the required depth of information as well as the time spans considered by offshore and onshore subgroups differed notably. In our sample, only CRTs required second by second updates on data during normal operations, whereas onshore engineers took a longer-term view of hours and days. This changed, when unexpected events occurred that could potentially compromise production or even endanger plant, personnel, or environment. Depending on the present situation or main activity, the required degree of interdependence and extent of coordination between subgroups could change substantially, and given the time- and safety-critical nature of the task these changes might occur very quickly and any time. In such events, teams move from a status with little need for overlap to a status, in which both subgroups need immediate and complete access to the same in-depth information.

The role of ICT in this change from normal to abnormal situations was demonstrated in an experimental study on process control operators by Nickel and Nachreiner (2008). Comparing performance of operators in normal and abnormal control situation using one or two visual units for the functional dynamic display of information, they found that time for fault management deteriorated in abnormal conditions if only one display was available. Thus, information that had been sufficient during normal operations turned out to be inadequate in critical conditions. In distributed ongoing coordination in production teams the situation is even more problematic, as here technology has to accommodate changing information requirements of subgroups with very different but highly inter-related tasks and perspectives. For the support of distributed ongoing teams such as oil production teams data presentation should thus be scalable with respect to type of information, amount, degree of detail, or time frames.

Our study also highlighted a conflict between media choices based on the normal role of organizational members and requirements in critical, but sporadic situations. Available data for onshore and offshore subgroups in the traditional setting, for instance, varied in detail (i. e., sampling rates), which could lead to different decisions for the same problem. In oil production teams onshore technical authorities generally made the decision, on whether a procedure is technically sound. While the onshore subgroups thus had the decision authority in terms of technical and legal standards, in some cases they lacked the adequate information to make such decisions in an informed way. Traditional ICT in our sample had been based on the primary role understanding of 'onshore planning' and 'offshore execution'. This example again demonstrates the need for flexibility and access for detailed data also for functions that do not usually require 
continuous detailed updates. It further highlights the challenge in distributed team coordination of balancing location of the richest information and locations at which decisions are made.

To remove the lacking transparency of processes we further argue that media should support social, action, and activity awareness, as well as the development of system knowledge between subgroups, e. g., by enabling more direct, real-time interactions. For more efficient sharing of information and perspectives media should also allow simultaneous operations and decisions by subgroups, for instance, by offering collective viewing and manipulation of data or visual information such as pictures or graphs and good quality video-conferencing to allow body language and physical pointers.

Technology should further be able to accommodate different and changing requirements for accessibility and privacy in the two subgroups or of one subgroup over time. As comments by offshore personnel showed, in times of high workload at the sharp end, continuous video-links can be a hindrance for concentrated work and thus add undue pressure. For this reason teams in our sample generally developed a protocol that on such occasions CRTs were encouraged to shut cameras off. Also decisions on where cameras are placed, the degree of resolution, or the remote controlling of camera angles are important aspects for regulating the amount of distraction, personal comfort in media environments, and the acceptance of new media (e. g., is it really necessary to see "every wart" on the nose of your communication partner; or should offshore technicians indeed be able to read emails on the PC screens of their colleagues onshore).

Another problem for the coordination between remote subgroups is the documentation of decisions. In oil production teams, for instance, onshore engineers are not as easily available during nights and weekends, although production still continues on the remote site. Decisions made during these times and their rationales must be comprehensible and reviewable by the other subgroup. Regular turnover in membership - in our case rotating shifts offshore-similarly challenges the continuity of processes. Decisions and procedures discussed with one shift were often not handed over fully to the next, and then had to be re-negotiated or explained again. While the verbal agreements, emails, or slide attachments used in our sample can be effective for teams with stable membership, these media were inadequate given the rotating shift system in oil production teams. To maintain efficient coordination, teams must thus be able to capture events and decisions taken by one subgroup in the absence of the other in sufficient detail for review or for other team members to take over without delay.

A recurring conflict for nearly all critical team activities was the tension between better coordination due to improved access to the remote subgroup, and possible distractions from the main job function (i. e., monitoring and controlling for CRTs, longer-term strategic work for onshore engineers), as well as the 
potential blurring of subgroups roles. Affordances of the new media clearly supported closer coordination and higher involvement between subgroups, and in many ways the new media provided considerable benefits for the coordination of tasks and processes. The potentially more problematic side effects did not become apparent until months after the implementation. At this point, technological changes in distributed team coordination clearly require a re-consideration of subgroup roles and responsibilities and the negotiation of usage rules - or a renewed discussion around the desirable features of media.

\section{Conclusion}

Olson and Olson (2000) discussed four concepts for successful distributed working: common ground, coupling of work, collaboration readiness, and collaboration technology readiness. They argued that remote working should succeed best if teams were loosely coupled, i. e., have fewer dependencies and rely mostly on routines, whereas high interdependency tasks should ideally be colocated. For tasks such as offshore oil production co-location clearly is not an option and accordingly, choosing ICT that can support highly-interdependent tasks in distributed settings is crucial. In our study we investigated the effects of different media capabilities on coordination in highly interlinked distributed production teams in the offshore oil industry. We further identified a number of challenges for the team functioning, when moving from one set of technologies to another. The technological change observed in this study altered existing routines, indicating that the organization of distributed working is very much a question of the available media capabilities. Our findings also showed that technology changes can modify the coupling within teams by shifting established roles of actors.

The present study used a longitudinal multi-layered approach in following teams for twelve months, observing their work in various situations, and collecting further insights through semi-structured interviews. For security and privacy reasons, we were not able to obtain systematic data on technology use (server statistics, email content, etc.), so our information relies mostly on subjective measures and incidental events during periods of observations. Although we feel that the length and approach of the present study provided us with a good basis for investigating the intricacies involved in remotely operating teams with highly interdependent tasks, further studies including more objective data on media type and usage could clearly broaden our understanding of effects of media capabilities on ongoing cooperation in distributed teams. Considering the impact of different media configurations and effects of changes in technology use over time in other industries that use distributed teams, could provide additional insights into the specific needs and challenges of supporting ongoing remote team cooperation. 


\section{Acknowledgments}

We thank Steve Sawaryn and Steve Goodwin, as well as TU Delft for their support of this research. We also thank two anonymous reviewers for their insightful comments and suggestions to improve this paper. An earlier version of this paper was presented at the CSCW 2008 Conference, San Diego, USA.

Open Access This article is distributed under the terms of the Creative Commons Attribution Noncommercial License which permits any noncommercial use, distribution, and reproduction in any medium, provided the original author(s) and source are credited.

\section{References}

Artman, H., \& Waern, Y. (1999). Distributed cognition in an emergency co-ordination centre. Cognition, Technology and Work, 1(4), 237-246.

Carroll, J. M., Neale, D. C., Isenhour, P. L., Rosson, M. B., \& McCrickard, D. S. (2003). Notification and awareness: synchronizing task-oriented collaborative activity. International Journal of Human Computer Studies, 58(5), 605-632.

Clark, H. H., \& Brennan, S. E. (1991). Grounding in communication. In L. B. Resnick, J. M. Levine, \& S. D. Teasley (Eds.), Perspectives on socially shared cognition (pp. 127-149). Washington, DC: American Psychological Association.

Clegg, C. W. (2000). Sociotechnical principles for system design. Applied Ergonomics, 31(5), 463-477.

Clement, A., \& Wagner I. (1995). Fragmented exchange: Disarticulation and the need for regionalized communication spaces. In EC-CSCW '95. Proceedings of the 4th European conference on computer-supported cooperative work, Stockholm, Sweden, September 11 to 15, 1995. Norwell: Kluwer, pp. 33-49.

Driskell, J. E., Hogan, R., \& Salas, E. (1987). Personality and group performance. In C. Hendrick (Ed.), Review of personality and social psychology (pp. 91-112). Newbury Park: Sage.

Fields, B., Amaldi, P., \& Tassi, A. (2005). Representing collaborative work: the airport as common information space. Cognition, Technology and Work, 7(2), 119-133.

Fiore, S. M., Salas, E., Cuevas, H. M., \& Bowers, C. A. (2003). Distributed coordination space: toward a theory of distributed team process and performance. Theoretical Issues in Ergonomics Science, 4(3-4), 340-364.

Glaser, B. G. (1992). Emergency versus forcing: Basics of grounded theory analysis. Mill Valley: Sociology.

Hammond, J. M., Harvey, C. M., Koubek, R. J., Compton, W. D., \& Darisipudi, A. (2005). Distributed collaborative design teams: media effects on design processes. International Journal of Human-Computer Interaction, 18(1), 145-165.

Harper, R. R., Hughes, J. A., Shapiro, D. Z. (1989). Working in harmony: An examination of computer technology in air traffic control. In EC-CSCW '89. Proceedings of the 1st European conference on computer-supported cooperative work, Sloug, UK, September 13 to 15, 1989. New York: ACM, pp. 73-87.

Heath, C., \& Luff, P. (1992). Collaboration and control: crisis management and multimedia technology in London underground control rooms. Computer Supported Cooperative Work, 1(1-2), 69-94.

Heyer, C. (2009). High-octane work: The oil and gas workplace. In ECSCW '09. Proceedings of the 11th European conference on computer-supported cooperative work, Vienna, Austria, September 7 to 11, 2009. London: Springer, pp. 363-383. 
Jarvenpaa, S. L., \& Leidner, D. E. (1999). Communication and trust in global virtual teams. Organization Science, 10(6), 791-815.

Johnsen, S. O., Ask, R., \& Roisli, R. (2007). Reducing risk in oil and gas production operations. In E. Goetz \& S. Shenoi (Eds.), Critical infrastructure protection (pp. 83-95). Boston: Springer.

Jones, D. G., \& Endsley, M. R. (1996). Sources of situation awareness errors in aviation. Aviation Space and Environmental Medicine, 67(6), 507-512.

Kirkman, B. L., Rosen, B., \& Tesluk, P. E. (2004). The impact of team empowerment on virtual team performance: the moderating role of face-to-face interaction. Academy of Management Journal, 47(2), 175-192.

Kirsch, C., Strohm, O., \& Ulich, E. (1994). Design of computer aided integrated manufacturing systems: Work psychological concepts and empirical findings. In G. Bradley \& H. W. Hendrick (Eds.), Human factors in organizational design and management IV (pp. 181-186). Amsterdam: North-Holland.

Lauche, K. (2008). Overcoming remoteness: human factors assessment of real-time monitoring and support in drilling operations. International Journal of Technology and Human Interaction, 4(1), 94-112.

Lavie, D. (2006). Capability reconfiguration: an analysis of incumbent responses to technological change. Academy of Management Review, 31(1), 153-174.

Nickel, P., \& Nachreiner, F. (2008). Evaluation of presentation of information for process control operations. Cognition, Technology and Work, 10(1), 23-30.

Olson, G. M., \& Olson, J. S. (2000). Distance matters. Human-Computer Interaction, 15(2-3), 139-178.

Pardo, O., Leder, L., \& Ulich, E. (1994). Between a market-oriented and a resource-based view: Use and development of skills and qualifications in connection with computer aided integrated manufacturing systems in small and medium sized companies. In G. Bradley \& H. W. Hendrick (Eds.), Human factors in organizational design and management IV (pp. 205-210). Amsterdam: North-Holland.

Patterson, E. S., \& Woods, D. D. (2001). Shift changes, updates, and the on-call architecture in space shuttle mission control. Computer Supported Cooperative Work, 10(3-4), 317-346.

Patterson, E. S., Watts-Perotti, J., \& Woods, D. D. (1999). Voice loops as coordination aids in space shuttle mission control. Computer Supported Cooperative Work, 8(4), 353-371.

Petterson, M., Randall, D., \& Helgeson, B. (2004). Ambiguities, awareness and economy: a study of emergency service work. Computer Supported Cooperative Work, 13(2), 125-154.

Sneddon, A., Mearns, K., \& Flin, R. (2006). Situation awareness and safety in offshore drill crews. Cognition, Technology and Work, 8(4), 255-267.

Thompson, J. D. (1967). Organizations in action: social science bases of administrative theory. New York: McGraw-Hill.

Van der Vegt, G. S., \& Janssen, O. (2003). Joint impact of interdependence and group diversity on innovation. Journal of Management, 29(5), 729-751.

Walsham, G. (1995). Interpretive case studies in is research: nature and method. European Journal of Information Systems, 4(2), 74-81.

Weber, W. G. (1997). Analyse von Gruppenarbeit. Kollektive Handlungsregulation in soziotechnischen Systemen. Bern: Huber.

Zölch, M. (1999). Gruppenübergreifende Zusammenarbeit bei der Werkstattsteuerung. In M. Zölch, W. Weber, \& L. Leder (Eds.), Praxis und Gestaltung kooperativer Arbeit (pp. 71-115). Zürich: vdf.

Zuboff, S. (1988). In the age of the smart machine: The future of work and power. New York: Basic Books. 